\title{
Household Level Drug Utilization and Associated Factors in South Gondar Zone, North Western Ethiopia
}

This article was published in the following Dove Press journal: Drug, Healthcare and Patient Safety
Introduction: Inappropriate drug utilization may reduce the best possible benefits of drug therapy, and patients may not be cured, they may be exposed to toxicity, and medications may be wasted. The aim of this study is to assess household-level drug utilization practices and their associated factors.

Methods: A cross-sectional community-based study was conducted from January 15 to March 15, 2020. In total, 847 households selected by stratified multistage sampling were visited. Bivariate and multivariable analyses for association were carried out using a binary logistic regression model. The statistical significance of an association was confirmed at $p<0.05$.

Results: Of the total 847 households, 378 (44.6\%) were found to store drugs at home at the time of datacollection. In the 371 households that allowed observation of the drugs stored, a mean of $2.51(\mathrm{SD}=1.68)$ drugs per household was found; $40.2 \%$ of stored medicines were not in use at the time of the study. The prevalences of medication hoarding, sharing, and allopathic self-medication were $20.4 \%, 26.3 \%$, and $43.8 \%$, respectively. Higher monthly income and the presence of a child aged under 5 years were significantly associated with drug hoarding. The presence of an elderly person aged above 65 years and the presence of a family member with chronic illness were significantly associated with drug hoarding and sharing. Families with higher educational status were less likely to hoard and share medicines. The presence of stored drugs at home was significantly associated with the practice of self-medication.

Conclusion: A high prevalence of inappropriate drug utilization was observed. Factors such as the presence of a family member with chronic illness, elderly people, and children under 5 , higher income, and the presence of stored drugs were significantly associated with inappropriate drug utilization. Families of higher educational status were less likely to hoard and share medicines.

Keywords: drug storage, medication hoarding, drug sharing, self-medication, Ethiopia
Correspondence: Amien Ewunetei Department of Pharmacy, College of Health Sciences, Debre Tabor University, Debre Tabor, 272, Ethiopia

Tel +251913670582

Email amienpeace@gmail.com

\section{Plain Language Summary}

People may not use drugs properly for various reasons. Thus, the optimal benefits of medications may not be obtained and users may be exposed to toxicity. The aim of this study was to assess drug utilization practices and related factors.

We gathered information from 847 households, and found that:

- $20.4 \%$ of the households stored at least one drug which was not in use currently

- $26.3 \%$ of the households shared drugs; two-thirds of them shared withe family members and one-third also shared outside the family

- $43.8 \%$ of households practiced self-medication. 
Factors associated with drug hoarding were:

- presence of a child under 5

- presence of an elderly person aged above 65 years

- presence of a family member with chronic illness

- higher monthly income.

Factors associated with drug sharing were:

- presence of an elderly person aged above 65 years

- presence of a family member with chronic illness.

Families with higher educational status were less likely to hoard and share medicines. Finally, the practice of self-medication using modern drugs was more likely to happen when there were stored drugs at home.

\section{Introduction}

The World Health Organization (WHO) defines drug utilization as "the marketing, prescribing, dispensing and use of drugs in society, with special emphasis on the resulting medical, social, and economic consequences". ${ }^{1}$ Hence, studies of drug utilization may evaluate the practice of medication prescribing, dispensing, or ultimate use by the end-user $\mathrm{s}$ of drugs. The customs and traditions of the society related to the utilization of medicines and associated factors can also be studied in the community, ${ }^{2,3}$ so that the prevalence of harmful drug utilization practices and their association with some determinant factors can be identified and ways of improving the practices can be designed. ${ }^{4}$

The rational use of drugs is an important part of any national health policy, and access to medicinal products is essential for enhancing and maintaining people's health. Inappropriate use of drugs is a global problem, which has a huge impact on health and economies; it adversely affects health-care systems in general and patients in particular. ${ }^{5-7}$ Inappropriate use of drugs may occur because of irrational prescribing, irrational dispensing, or irrational patient use. ${ }^{8,9}$ The best possible benefits of drug therapy in patient care in any community may not be attained because of the irrational use of medicines. ${ }^{4}$

One of the improper drug uses is premature cessation of a treatment course, when patients feel that their symptoms have subsided and keep the rest of the medication for future use. ${ }^{10-15}$ Other forms of improper drug use are medication hoarding, sharing, and risky self-medication with prescription drugs. Drug sharing may be practiced with family members and with relatives, neighbors, and friends. ${ }^{15,16}$ People usually keep stocks of leftover drugs in their homes and reuse them or give to neighbors, friends, or relatives who request them. These practices are also common in countries where dispensing of drugs is regulated more strictly. In many nations, people can buy drugs over the counter which legally should be sold only on prescription. Self-medication with prescription drugs is risky, especially in developing nations where pharmacies can freely sell drugs over the counter, as do unauthorized drug shops and grocery stores. Sometimes people even self-medicate with prescription drugs based on the instruction of traditional healers. ${ }^{4}$ Self-medication with antibiotics is frequent in communities of developing nations of the world. ${ }^{17}$ When people are unable to afford a full treatment course of antibiotics, they usually buy the dosage regimen in smaller quantities, or they may not be able to pay for all the drugs that are prescribed. ${ }^{4,15,18-21}$ The practice of allopathic self-medication may also be predicted by a low severity of illness ${ }^{22}$ and the easy accessibility of medications from informal sectors such as village kiosks and open markets. ${ }^{23}$

Patients may fail to remember the details of the medication advice provided to them and do not always adhere to the prescribed drug regimen. They often take medications in the wrong way, such as reducing dose to make the treatment last longer or increasing the dose in the hope of a faster cure. This occurs because most patients do not clearly understand the mechanism of action of drugs in the body. In support of all these improper uses of medications, WHO reported that $50 \%$ of all patients take their medication incorrectly. ${ }^{8}$ As a result, they sometimes face therapeutic failure, poor treatment outcomes, adverse drug reactions, and/or toxicity. The emergence of resistance for antibiotics, increased cost, inappropriate storage, expiry, and wastage of drugs are also reported to be results of improper drug use. ${ }^{4,24}$

Drug hoarding, sharing, and self-medication practices are prevalent in Ethiopia. Some of these practices are reported to be harmful and they need prompt action. These practices vary in different populations and regions of the country. ${ }^{10,25,26}$ Patterns of drug utilization may vary among different areas and communities or at different times. Geographical differences and variations in drug utilization over time should be identified, because these may have medical, social, and economic implications both for individual patients and for society. ${ }^{1}$ Since no study has been conducted to assess the practices of drug utilization and because information is limited on drug use habits in the study area, it was felt that the drug utilization practices 
and related factors need to be assessed to eliminate dangerous trends in drug utilization. The aim of this study was, therefore, to evaluate the household-level drug utilization practices and associated factors in South Gondar zone, Ethiopia.

\section{Operational Definitions}

Drug utilization: The practice of drug hoarding, drug sharing and self-medication using modern drugs.

Stored drug: Any drug observed in the home during data collection, excluding contraceptives.

Drug/medication hoarding: Storing at least one drug (leftover and/or newly received), which is not currently in use but kept without purpose or for anticipated future use.

Drug sharing: The sharing of drugs for therapeutic or prophylaxis purposes among family members, relatives, friends, or neighbors.

Allopathic self-medication: The use of modern drugs (excluding home remedies, holy water, and traditional healers) for illness within a two-week recall period without the recommendation of health-care professionals.

Risky self-medication: The use of prescription drugs to self-medicate.

Chronic illness: Prolonged illness that may persist for more than a year and may not be cured.

Kebele: The smallest governmental administrative unit in Ethiopia.

\section{Methods}

\section{Study Area}

The study was conducted in South Gondar zone, which is one of the governmental administrative zones of Amhara Region in Ethiopia. Debre Tabor town, located $666 \mathrm{~km}$ from the capital city of Addis Ababa and $103 \mathrm{~km}$ from Bahir Dar to the north west, is the capital of the zone. South Gondar zone is bordered to the south by East Gojam, to the west by Lake Tana, to the north by North Gondar, and to the east by North Wollo. The zone is organized into 18 (five urban and 13 rural) districts.

According to the national census conducted in 2007 by the Central Statistical Agency (CSA) of Ethiopia, this zone has a total population of 2,051,738, of whom 1,041,061 are men and 1,010,677 women. Only 195,619 (9.53\%) are urban inhabitants. The total number of households in this zone is 468,238 , which results in an average of 4.38 persons per household. There are 96 health centers, seven primary hospitals, and one general hospital in the zone.

\section{Study Design and Population}

A community-based cross-sectional study was conducted from January 15 to March 15, 2020. The source population was all households in South Gondar zone.

\section{Inclusion Criteria}

All households (families) that had lived in the study area for at least 6 months were included.

\section{Sample Size Determination and Sampling Procedures}

The sample size was estimated using a single population proportion formula with 5\% margin of error and 95\% confidence level. In a study conducted in the town of Nekemte and nearby rural areas in Ethiopia in 2012, the prevalences of drug hoarding, sharing, and self-medication were $49.9 \%, 24.9 \%$, and $36.3 \%$, respectively. ${ }^{26}$ The prevalence of drug hoarding yields the largest sample size, which is 385 . A design effect of 2 and $10 \%$ compensation for non-response were considered, and the final sample size was determined to be 847 .

Stratified multistage sampling was a practical means of sampling the households in this study. There are 18 districts and 405 kebeles in South Gondar zone, of which 364 are rural kebeles and 41 are urban. Accordingly, the kebeles in the zone were stratified into urban and rural. In the first stage, one rural kebele and one urban kebele were sampled randomly in each district. This resulted in 36 randomly selected kebeles. Then, after conducting a census in each kebele, the total sample size (847) was allocated in proportion to the number of households in each kebele. In the second stage, household units were selected by a simple random sampling method.

\section{Study Variables}

The dependent variables were drug hoarding, drug sharing, and allopathic self-medication.

Independent variables were residence, sex, religion, occupation of the head of the household, income, educational status of the head of the household, highest educational level in the family, family size, presence of children aged under 5 years in the family, presence of elderly people, presence of family members with chronic illness, presence of health professionals in the family, and presence of stored drugs. 


\section{Data Collection Instrument, Personnel, and Procedures}

After a thorough review of the literature, a semi-structured interviewer-administered questionnaire consisting of closed and open-ended questions and a structured observational checklist were used for data collection. Questions were arranged based on the particular objective to be addressed. The questionnaire was initially developed in English and then translated to Amharic (the local language). Pretesting of the data collection instrument was conducted in one of the non-selected kebeles and proper improvements were made to obtain the final version.

Eleven data collectors and four supervisors (pharmacists and pharmacy technicians) were recruited to collect the data. Training for supervisors and data collectors was provided for one day. In addition to the four supervisors, the principal investigators carried out on-site supervision.

The data were collected through face-to-face interviews and observation. Interviewees were available adult family members in the selected households at the time of data collection. When more than one adult family member was available, the one deemed more conversant was given priority. Second visits to the households were made when eligible adults were not available for interview and/or whenever incomplete questionnaires were identified. Contraceptives were not counted as drugs in this study.

\section{Data Processing and Analysis}

The data were cleaned, coded, and entered into Epi Info version 3.5.3, and exported to SPSS for Windows version 20 to conduct analyses. Appropriate descriptive analysis was performed by calculating frequencies, means, and proportions. The results were presented as text and in the form of tables and graphs. Bivariate and multivariable analyses were carried out using a binary logistic regression model in the analysis of the association between independent and outcome variables. Statistical significance of associations was confirmed at $p<0.05$. Odds ratios with their $95 \%$ confidence levels were taken as indicators of the strength of associations.

\section{Results}

\section{Socio-Demographic Profiles of the Study} Participants and Households

Out of 847 households visited, 157 (18.5\%) were urban and $690(81.5 \%)$ were rural. The majority of the respondents interviewed, $745(88 \%)$, were heads of households and the rest were other family members. Of the total households, $741(87.5 \%)$ of the heads of households were males and $106(12.5 \%)$ were females. Most of the respondents, 822 (97\%), were Orthodox Christians, 23 $(2.7 \%)$ were Muslims, and two $(0.2 \%)$ were Protestants. In terms of occupation, $692(81.7 \%)$ of the heads of households were farmers. The mean (SD) family size of the population under study was 5.17 (1.95) people. Of the total surveyed households, $473(55.8 \%)$ had a family size of four to six people (Table 1).

\section{Household Drug Storage and Hoarding}

Of the total 847 household units included in the analysis, $378(44.6 \%)$ were found to keep drugs at home during data collection. However, it was not possible to observe the stored medicines in seven $(1.9 \%)$ of the households. In the 371 households where the data collectors were able to see drugs stored, an average of $2.51 \quad(\mathrm{SD}=1.68)$ drugs per household were found and the total number of medications stored was 932, of which $375(40.2 \%)$ were not in use at the time of the study and the remaining 557 (59.8\%) were found to be in use by the person for whom they were initially intended or by another person who shared the medication. Looking at the number of medications stored in each household, more than half $(60.6 \%)$ of the households stored one or two medicines at home (Figure 1).

At least one leftover or newly received drug that was not currently in use was found to be stored in 173 (20.4\%) of the 847 households and in $173(45.8 \%)$ of the 378 households which kept medicines at home at the time of data collection. Thus, the prevalence of drug hoarding at home was found to be $20.4 \%$ (95\% CI $17.8-23.0$ ); 111 $(64.2 \%)$ of 173 households hoarded drugs with the intention of future use and $62(35.8 \%)$ of them kept drugs without purpose. At least one expired drug (including an unreadable expiry date) was observed in $87(10.3 \%)$ of the surveyed households where observation of any stored drugs was possible.

Anti-infectives (antibacterials, antivirals, antiprotozoals, anthelmintics, antifungals) were found to be highly stored (427 [45.8\%]) types of drugs at the household level, and analgesics and non-steroidal anti-inflammatory drugs (NSAIDs), such as paracetamol, tramadol, diclofenac, and ibuprofen, were the second most stored (196 [21.0\%]) drug classes. The other classes of drugs found were gastrointestinal drugs (11.2\%), nervous system drugs (6.7\%), cardiovascular drugs and diuretics $(4.9 \%)$, drugs used for endocrine disorders $(3.1 \%)$, antihistamines and respiratory drugs $(1.8 \%)$, vitamins $(1.3 \%)$, and others $(2.2 \%)$ 
Table I Socio-Demographic Characteristics of Study Participants and Households in South Gondar Zone, NorthWestern Ethiopia, $2020(N=847)$

\begin{tabular}{|c|c|c|c|}
\hline \multicolumn{2}{|l|}{ Variables } & Frequency & Percent \\
\hline Residence & Urban & 157 & 18.5 \\
\hline & Rural & 690 & 81.5 \\
\hline \multirow[t]{2}{*}{ Role of the respondent in the household } & Head of the household & 745 & 88 \\
\hline & Other family member & 102 & 12 \\
\hline \multirow[t]{2}{*}{ Sex of the household head } & Male & 741 & 87.5 \\
\hline & Female & 106 & 12.5 \\
\hline \multirow[t]{3}{*}{ Religion of the household head } & Orthodox & 822 & 97.0 \\
\hline & Muslim & 23 & 2.7 \\
\hline & Protestant & 2 & 0.2 \\
\hline \multirow[t]{6}{*}{ Occupational status of the household head } & Farmer & 692 & 81.7 \\
\hline & Government worker & 29 & 3.4 \\
\hline & Merchant/private & 89 & 10.5 \\
\hline & business & & \\
\hline & Housewife & II & 1.3 \\
\hline & Daily laborer & 26 & 3.1 \\
\hline \multirow[t]{5}{*}{ Educational status of the household head } & Cannot read and write & 232 & 27.4 \\
\hline & Can read and write & 418 & 49.4 \\
\hline & Grade I-8 & 126 & 14.9 \\
\hline & Grade 9-12 & 37 & 4.4 \\
\hline & Above grade 12 & 34 & 4.0 \\
\hline \multirow[t]{5}{*}{ Highest educational status in the family } & Cannot read and write & 31 & 3.7 \\
\hline & Can read and write & 79 & 9.3 \\
\hline & Grade I-8 & 361 & 42.6 \\
\hline & Grade 9-12 & 221 & 26.1 \\
\hline & Above grade 12 & 155 & 18.3 \\
\hline \multirow[t]{3}{*}{ Monthly income of the household } & $<1500$ Birr & 370 & 43.7 \\
\hline & $1500-5000$ Birr & 328 & 38.7 \\
\hline & $>5000$ Birr & 149 & 17.6 \\
\hline \multirow[t]{4}{*}{ Family size } & $\leq 3$ & 162 & 19.1 \\
\hline & $4-6$ & 473 & 55.8 \\
\hline & $7-9$ & 204 & 24.1 \\
\hline & $\geq 10$ & 8 & 0.9 \\
\hline \multirow[t]{2}{*}{ Is there a child in the household with an age of less than 5 years? } & No & 445 & 52.5 \\
\hline & Yes & 402 & 47.5 \\
\hline \multirow[t]{2}{*}{ Is there a family member with an age of more than 65 years? } & No & 677 & 79.9 \\
\hline & Yes & 170 & 20.1 \\
\hline \multirow[t]{2}{*}{ Are there any family members with chronic illness? } & No & 759 & 89.6 \\
\hline & Yes & 88 & 10.4 \\
\hline \multirow[t]{2}{*}{ Are there any health professionals in the family? } & No & 798 & 94.2 \\
\hline & Yes & 49 & 5.8 \\
\hline
\end{tabular}




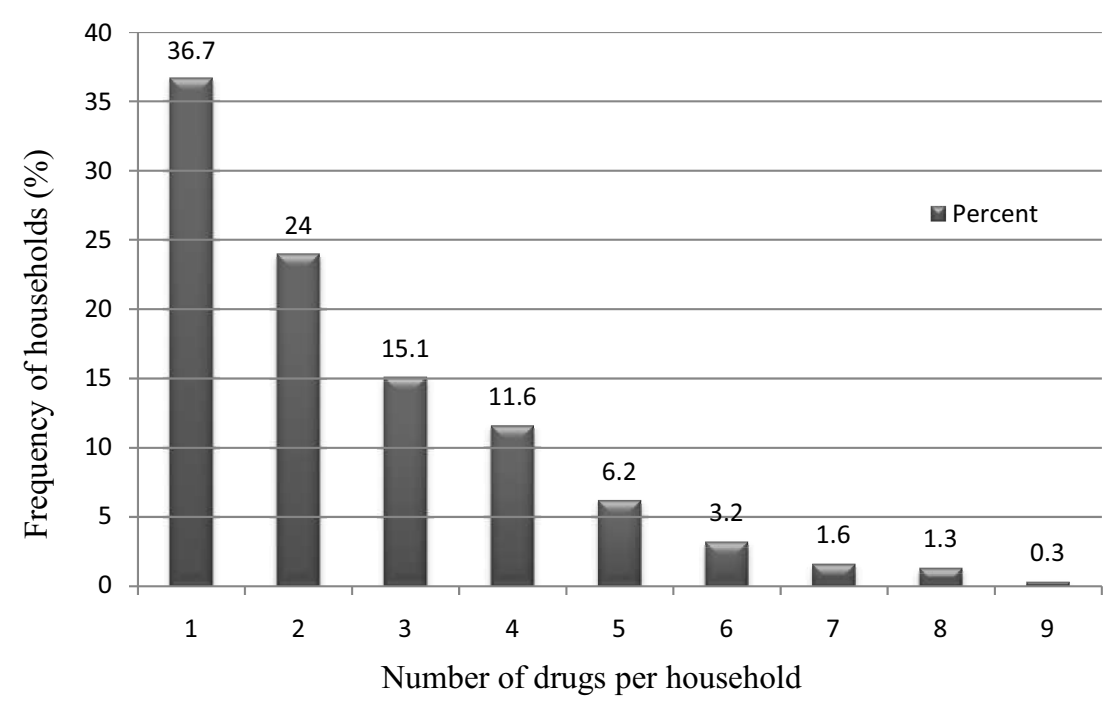

Figure I Percentage distribution of households by number of drugs stored, South Gondar zone, NorthWestern Ethiopia, 2020 (N=37I).

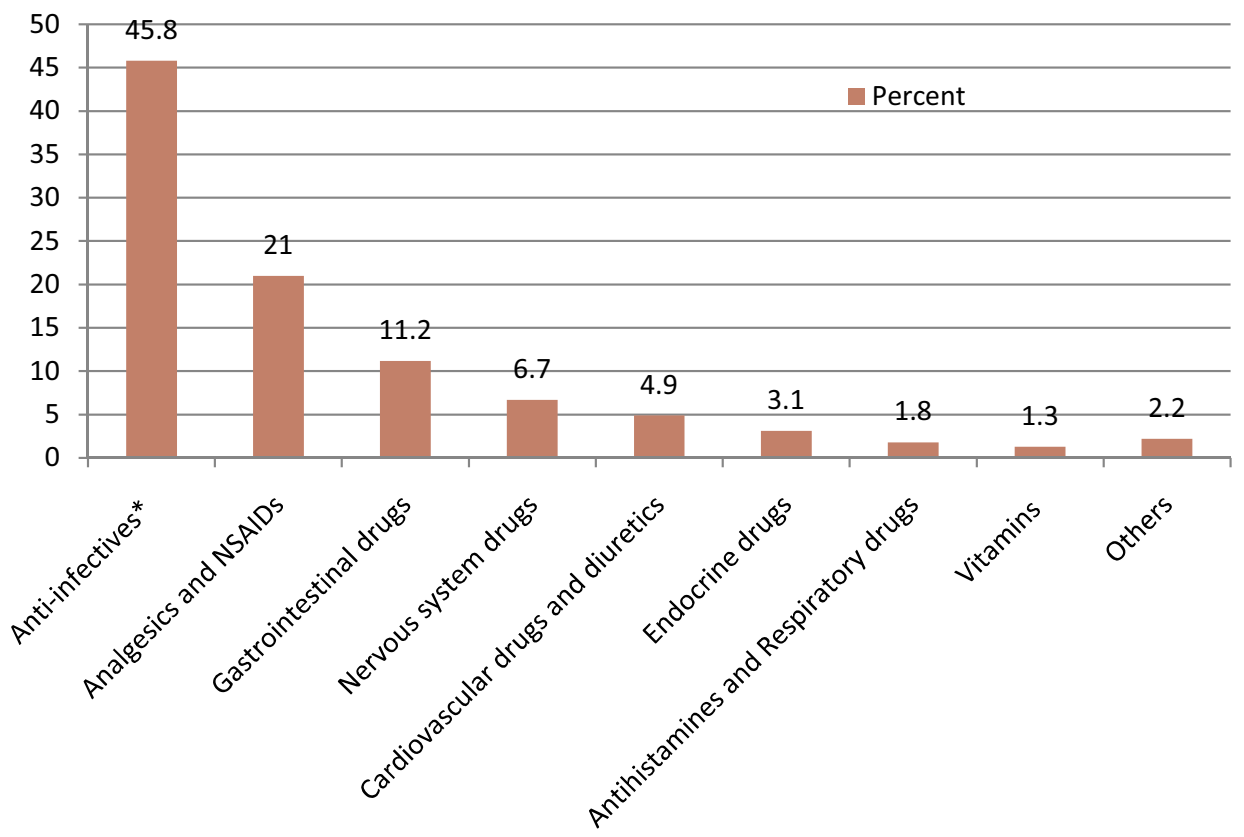

* Includes antibacterials, antivirals, antiprotozoals, antihelmentics, antifungals

Figure 2 Classes of drugs stored in households at the time of data collection, South Gondar zone, NorthWestern Ethiopia, 2020.

(Figure 2). Nineteen $(2.0 \%)$ of all the medications stored were not identified because their labeling was unavailable. Most of the stored drugs were found in the form of tablets (485 [52\%]) and capsules (284 [30.5\%]) (Figure 3).

\section{Factors Associated with Drug Hoarding}

During the bivariate analysis, being an urban resident, the presence of a child with an age of less than 5 years, higher monthly income, the head of the family having an occupational status of either government worker or merchant, having a family member with educational status above grade 12, a higher family size, the presence of an elderly person aged above 65 years, the presence of a family member with chronic illness, and the presence of a health professional in the family were associated with drug hoarding. Finally, during the multivariable binary logistic regression analysis, the presence of a child under 5 years of age $(\mathrm{AOR}=2.518 ; 95 \% \mathrm{CI}$ 


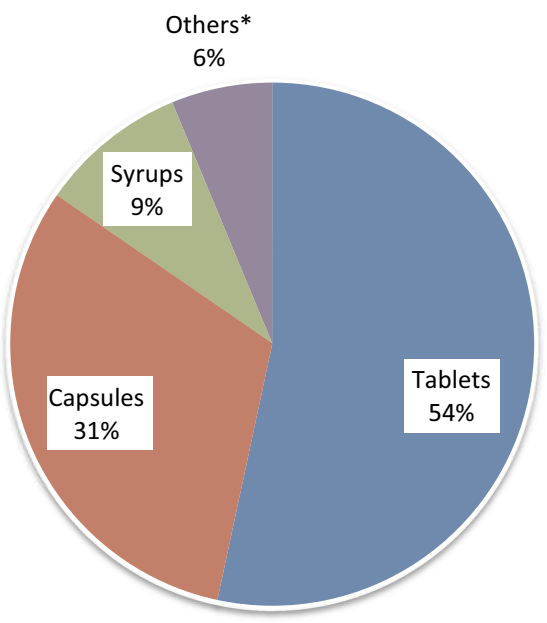

* Includes suppositories, inhalers, topically applied creams and ointments, eye drops and insulin injections etc.

Figure 3 Dosage forms of drugs stored in households at the time of data collection, South Gondar zone, North Western Ethiopia, 2020.

1.649-3.847), the presence of an elderly person above 65 years of age $(\mathrm{AOR}=2.531 ; 95 \%$ CI $1.622-3.951)$, the presence of a family member with chronic illness (AOR=3.263; 95\% CI 1.849-5.761), and higher monthly income ( $\geq 1500$ birr) (AOR=2.877; 95\% CI 1.69-4.9) were found to be significantly associated with medication hoarding at home, but households with the ability to read and write as the highest educational status in the family were $88.3 \%$ less likely to hoard drugs
(AOR $=0.117 ; 95 \%$ CI $0.017-0.819)$ compared to households with not being able to read and write as the highest educational status in the family (Table 2). The model explained $34.8 \%$ (Nagelkerke $R^{2}$ ) of the variance in drug hoarding and correctly classified $83.1 \%$ of the cases.

\section{Drug Sharing and Its Associated Factors}

Drug sharing was reported to be practiced among 223 of the 847 surveyed households. Therefore, the prevalence of sharing drugs was found to be $26.3 \%$ (95\% CI 23.7-29.4). Of these households, 148 (66.4\%) shared drugs among the family members and $75(33.6 \%)$ also shared drugs outside the family.

In the bivariate analysis, being a rural resident, having a low average monthly income, having a farmer as the head of the household, in terms of occupation, having family members who are not able to read and write, a smaller family size, the presence of an elderly person aged above 65 years, the presence of a family member with chronic illness, and the absence of a health professional in the family were associated with drug sharing practices. Finally, in the multivariable regression analysis, the presence of an elderly person more than 65 years of age $(\mathrm{AOR}=2.167 ; 95 \%$ CI 1.401-3.351) and the presence of a family member with chronic illness $(\mathrm{AOR}=4.736$; 95\% CI 2.614-8.579) were significantly associated with drug sharing. Compared to those who were not able to

Table 2 Factors Associated with Medication Hoarding at Household Level in South Gondar Zone, North Western Ethiopia, 2020

\begin{tabular}{|c|c|c|c|c|c|}
\hline \multicolumn{2}{|l|}{ Variables } & \multirow{3}{*}{$\begin{array}{c}p \text {-Value } \\
0.000\end{array}$} & \multirow{3}{*}{$\begin{array}{l}\text { AOR } \\
2.518\end{array}$} & \multicolumn{2}{|c|}{ 95\% Cl for AOR } \\
\hline & & & & Lower & Upper \\
\hline Is there a child in the household with an age of less than 5 years? & $\begin{array}{l}\text { No } \\
\text { Yes }\end{array}$ & & & 1.649 & 3.847 \\
\hline What is the average monthly income of the family? & $\begin{array}{l}<1500 \text { Birr } \\
1500-5000 \text { Birr } \\
>5000 \text { Birr }\end{array}$ & $\begin{array}{l}0.000 \\
0.000 \\
0.004\end{array}$ & $\begin{array}{l}2.877 \\
2.585\end{array}$ & $\begin{array}{l}1.690 \\
1.345\end{array}$ & $\begin{array}{l}4.900 \\
4.970\end{array}$ \\
\hline What is the highest educational status in the family? & $\begin{array}{l}\text { Cannot read and write } \\
\text { Can read and write } \\
\text { Grade } 1-8 \\
\text { Grade } 9-12 \\
\text { Above } 12\end{array}$ & $\begin{array}{l}0.102 \\
0.031 \\
0.091 \\
0.298 \\
0.573\end{array}$ & $\begin{array}{l}0.117 \\
0.299 \\
0.447 \\
0.617\end{array}$ & $\begin{array}{l}0.017 \\
0.074 \\
0.098 \\
0.115\end{array}$ & $\begin{array}{l}0.819 \\
1.213 \\
2.039 \\
3.307\end{array}$ \\
\hline Is there a family member with an age of more than 65 years? & $\begin{array}{l}\text { No } \\
\text { Yes }\end{array}$ & 0.000 & 2.531 & 1.622 & 3.951 \\
\hline Are there any family members with chronic illness? & $\begin{array}{l}\text { No } \\
\text { Yes }\end{array}$ & 0.000 & 3.263 & 1.849 & 5.761 \\
\hline
\end{tabular}

Notes: Hosmer and Lemeshow test, $p=0.638$; Nagelkerke $R^{2}=0.348$. 
Table 3 Factors Associated with Drug Sharing at Household Level in South Gondar Zone, NorthWestern Ethiopia, 2020

\begin{tabular}{|c|c|c|c|c|c|}
\hline \multicolumn{2}{|l|}{ Variables } & \multirow{2}{*}{ p-Value } & \multirow[t]{2}{*}{ AOR } & \multicolumn{2}{|c|}{ 95\% CI for AOR } \\
\hline & & & & Lower & Upper \\
\hline \multirow[t]{5}{*}{ What is the highest educational status in the family? } & Cannot read and write & 0.000 & & & \\
\hline & Can read and write & 0.100 & 0.484 & 0.204 & 1.150 \\
\hline & Grade I-8 & 0.008 & 0.322 & 0.140 & 0.743 \\
\hline & Grade 9-12 & 0.000 & 0.088 & 0.031 & 0.255 \\
\hline & Above grade 12 & 0.000 & 0.023 & 0.005 & 0.094 \\
\hline \multirow[t]{2}{*}{ Is there a family member with an age of more than 65 years? } & No & & & & \\
\hline & Yes & 0.001 & 2.167 & 1.401 & 3.351 \\
\hline \multirow[t]{2}{*}{ Are there any family members with chronic illness? } & No & & & & \\
\hline & Yes & 0.000 & 4.736 & 2.614 & 8.579 \\
\hline
\end{tabular}

Notes: Hosmer and Lemeshow test, $p=0.382$; Nagelkerke $R^{2}=0.208$.

read and write, households with the highest educational levels of grade $1-8$, grade $9-12$, and grade above 12 were $67.8 \% \quad(\mathrm{AOR}=0.322 ; 95 \% \quad \mathrm{CI} \quad 0.140-0.743), \quad 91.2 \%$ $(\mathrm{AOR}=0.088 ; \quad 95 \% \quad \mathrm{CI} \quad 0.031-0.255), \quad$ and $97.7 \%$ (AOR $=0.023 ; 95 \%$ CI $0.005-0.094$ ) less likely to share medicines, respectively (Table 3 ). The model explained $20.8 \%$ (Nagelkerke $R^{2}$ ) of the variance in drug sharing and correctly classified $75.6 \%$ of cases.

\section{Self-Medication Practice and Associated} Factors

There were family members with a new episode of illness within the past 2 weeks in $137(16.2 \%)$ of the surveyed households. There was a report of self-medication with modern drugs in 60 of these households, making the prevalence of household-level self-medication $43.8 \%$ (95\% CI 35.8-51.8). Some other measures taken for the new episode of illness were visiting health facilities, going to traditional healers, using home remedies, and baptizing with holy water in $27(19.7 \%), 12$ (8.8\%), 23 (16.8\%), and $35(25.5 \%)$ of the households, respectively. Ten $(7.3 \%)$ of the households did nothing to treat the illness. Out of the households that reported self-medication with modern drugs, newly received drugs were taken in 20 (33.3\%) of the households, hoarded drugs were taken in $30(50.0 \%)$, and shared drugs (not prescribed for the ill person) were taken in $24(40.0 \%)$ of the households.

In the bivariate regression analysis, being an urban resident, higher monthly income, the household head having an educational level above grade 12, higher family size, the presence of a family member with an age of more than 65 years, the presence of a family member with chronic illness, and the presence of a stored drug were found to be significantly associated with the practice of allopathic self-medication. However, only the presence of a stored drug was significantly associated $(\mathrm{AOR}=18.6$; 95\% CI 4.9-70.4) with self-medication when the multivariable regression analysis was run. Households with stored drugs were 18.6 times more likely to practice allopathic self-medication than households without any stored drugs. The model correctly classified $80 \%$ of cases and explained $52 \%$ (Nagelkerke $R^{2}$ ) of the variance in selfmedication.

\section{Discussion}

During this survey, $378(44.6 \%)$ of the total surveyed households were found to store drugs at home. On one hand, this proportion was lower than in some regions or nations of the world, such as Sudan (97.7\%), Tanzania (73.3\%), Sahrawi refugee camps in Tindouf, Algeria $(89.5 \%)$, Indonesia (82\%), Pakistan (64.2\%), Iran $(>82.4 \%, 100 \%)$, Saudi Arabia and Arabian gulf countries (99.68\%), Iraq (94\%), Oman (95\%), Greece (100\%), Brazil $(91.1 \%$ of households served by the family health strategy), and the USA (81.5\%). ${ }^{12,15,16,18,27-35}$ This difference in the extent of drug storage may be because of the dissimilarities in cultural aspects and levels of socioeconomic development in these regions. Individuals in some countries have better access to medicines and frequently use allopathic medication to treat any ailments. Other countries have family health strategies and health insurance schemes which may influence the drug use behavior of families. Moreover, the practice of selfmedication among communities or countries varies, which may affect the extent of medication storage. On 
the other hand, the result of this study was elevated compared to findings from Northern Uganda (35.1\%), as well as Addis Ababa (20\%) and Tigray (29\%) in Ethiopia; ${ }^{10,36,37}$ but it was comparable to a finding in Nigeria (42.1\%) and two other studies in Ethiopia, one study in Gondar town (44.2\%) and a study from Western Ethiopia (49.9\%). ${ }^{26,38,39}$

A mean of $2.51(\mathrm{SD}=1.68)$ medications per household was found in the 371 households in this study. This was lower than study findings in Uganda, Oman, Iraq, Greece, Iran, and Saudi Arabia, where the mean number of medications per household was found to be $6.00,6.00,14.26$, $8.50,22.99$, and 8.00, respectively. ${ }^{29-31,35,36,40}$ The variation here could also be attributed to the above-stated differences between Ethiopia and these countries. One study from Nigeria reported a similar average number of medicines (2.3) stored per household; ${ }^{39}$ two studies in two towns of Ethiopia, however, reported slightly lower average numbers of medications per household (1.8 and 1.73) compared to the present finding. ${ }^{26,37}$ According to some reports, a high number of medicines stored in the home is associated with a high prevalence of self-medication, which may be risky. ${ }^{20,36}$

In this study, the total number of medicines stored was 932, of which $557(59.8 \%)$ were in use at the time of the survey. This is similar to results from studies in Tanzania $(64.7 \%)$ and the Tigray region of Ethiopia (62\%), ${ }^{16,37}$ but two times higher than a result from Iraq (31\%). ${ }^{29}$ Concerning the number of medicines stored in each household, more than half $(60.6 \%)$ of these households stored one or two medicines. Of the stored drugs, 427 (45.8\%) were found to be anti-infectives, and analgesics and NSAIDs were the second most stored $(21.0 \%)$ classes of drugs. Some studies reported the most stored drug classes as antibacterials or antibiotics or anti-infectives, ${ }^{29,36}$ and other studies reported analgesics as the most commonly kept type of drug class at home. ${ }^{26,28,37}$ Anti-infectives cover a wider range of drugs and include antibacterials, antivirals, antiprotozoals, anthelmintics, and antifungals. This wider range was clearly attributed to the elevated figure $(45.8 \%)$ showing a higher extent of storage for antiinfectives. Studies may count and record drugs used for infectious diseases separately as antibiotics, antibacterials, antimalarials, etc., to determine the extent of their storage and compare it with others. In addition, in some studies, analgesics may represent only central nervous system (CNS) drugs excluding NSAIDs. This results in big discrepancies in the figures of drug storage reports from a variety of studies.

At least one expired drug (including an unreadable expiry date) was observed in $87(10.3 \%)$ of the surveyed households where observation was possible. Many studies have reported the proportion of expired drugs, whereas this study reported the proportion of households with at least one expired drug. A study in Northern Ethiopia showed that $5 \%$ of the stored drugs were found to be expired. ${ }^{37}$ However, high proportions of expired drugs were also reported in research conducted in different nations in the Middle East and Sudan. ${ }^{15,29,30,35,40}$

The prevalence of drug hoarding found in this study (20.4\%) was similar to a result obtained from a study conducted in Addis Ababa, Ethiopia $(20 \%),{ }^{10}$ but it was lower than in a study carried out in Nekemte, Western Ethiopia (49.9\%). ${ }^{26}$ It was noted that drugs used for ongoing treatment were included in calculating the prevalence of drug hoarding in the latter study. In this study, however, drug hoarding was calculated by excluding drugs that were in use at the time of the data collection. This obviously makes a difference in reports on the prevalence of drug hoarding. Some studies conducted in Vietnam, Iran, Oman, and the USA reported higher values (27-$82 \%$ ), which may be attributed to people's access to drugs and the medication storage behavior of the community. ${ }^{12,20,30,32}$ In other studies, high proportions of stored drugs were reported to be hoarded compared to drugs for ongoing treatment. For instance, proportions of stored drugs hoarded at home were reported to be $52 \%$ in Uganda, $35.3 \%$ in Tanzania, $68 \%$ in Iraq, and $38 \%$ in Northern Ethiopia. ${ }^{16,29,36,37}$

In terms of the likelihood of hoarding medicines which are not in use currently, households with a child aged less than 5 years, households with a family member aged above 65 years, and households with a family member with illness were more likely to hoard medications than those without such individuals in the family. The reason for this may be that these groups of family members are vulnerable to illnesses which increase the probability of dealing with drugs. Higher monthly income was also found to be associated with a higher likelihood of drug hoarding. Similar findings have been reported by other studies. $^{36,40}$ The study found that the prevalence of drug sharing practices was $26.3 \%$, which is equivalent to a finding reported from a study in Nekemte $(24.9 \%) .{ }^{26}$ But studies conducted in Gondar and Addis Ababa reported the prevalence of drug sharing as $17.8 \%$ and $17 \%$, 
respectively. ${ }^{10,41}$ These two studies did not include rural areas, Gondar is a town and Addis Ababa is the capital city of Ethiopia, and the disagreement may be attributed to the relative accessibility of health-related facilities and diversity in socio-economic status of the study communities. A study from Tanzania reported that drug sharing among family members or outside the family was exercised by $12 \%$ of the surveyed households, ${ }^{16}$ but a survey from Sudan revealed a higher percentage (59.3\%) of drug exchange among the surveyed households. ${ }^{15}$ In this study, $66.4 \%$ of the 223 households shared drugs within the family and $33.6 \%$ of them also shared drugs outside the family. A study conducted in Greece showed that 95\% of households exchanged drugs within the family while $17.5 \%$ of families exchanged drugs across relatives, friends, and neighbors. ${ }^{31}$

Previous studies revealed that medication sharing was associated with residence, education, age, sex, and marital status. $^{10,26}$ In this study, sharing medications was significantly associated with the presence of a family member aged above 65 years, the presence of a family member with chronic illness, and not being able to read and write as the highest level of education in the family.

In this study, the prevalence of allopathic selfmedication was found to be $43.8 \%$. This result is comparable with findings of studies in Sudan, where $46.9 \%$ of households reported self-medication, in Nigeria, where $44.3 \%$ of ill people self-treated, and in Asendabo, Ethiopia, where $39 \%$ of households used self-medication for a two-week recall period of illness. ${ }^{15,22,39}$ Lower results were also reported in studies from Brazil (16.1\%), Chile (30\%), Pakistan (15.7\% for urban areas and 8.3\% for rural areas), Nekemte, Ethiopia (36.3\%), and Jimma, Ethiopia $(27.6 \%) .^{18,26,42-44}$ On the other hand, the prevalence in a report from Iran (53.6\%) is slightly higher than the result of this study, and figures from Tanzania $(83 \%)$, Uganda (76\%), India (73.1\%), Iraq (78\%), and Nigeria $(95 \%)$ are higher than the findings of this study. ${ }^{16,21,28,29,36,45}$ Measures taken for new episodes of illnesses vary across communities. Going to health institutions is the primary action taken in some areas but it may be the last option in others. In this study, visiting health facilities was reported in only $19.7 \%$ of households with a new episode of illness in a two-week recall period, and $7.3 \%$ of the households did nothing for the illness. According to a study carried out in Addis Ababa in 1997, with a four-week recall period of illness, $26 \%$ of respondents did not take any action for their illness. ${ }^{10}$ The discrepancy may be due to the time gap between the two studies being conducted.

This survey also found that allopathic self-medication was significantly associated with the presence of stored drugs at home $(\mathrm{AOR}=18.6 ; 95 \%$ CI 4.9-70.4). In support of this, out of the households that reported self-medication with modern drugs, hoarded drugs were taken in $50.0 \%$; and shared drugs (not prescribed for the ill person) were taken in $40.0 \%$ of the households. Studies in Vietnam and Brazil reported similar findings, where the practice of selfmedication increases when drugs are kept in the house. $^{20,46}$ Studies conducted in Nekemte, Ethiopia, and Nigeria, however, revealed that the level of selfmedication was associated with age. ${ }^{26,45}$

\section{Conclusion}

Drugs were found to be stored in nearly half of the surveyed households, with anti-infective medicines being the most commonly stored class of medicines. Drug hoarding, sharing, and allopathic self-medication were found to be prevalent, which indicates the presence of unnecessary storage of drugs aimlessly or with intent of future use, inappropriate drug sharing, and risky self-medication with modern drugs. The presence of elderly people with age above 65 years and the presence of family members with chronic illness were significantly associated with drug hoarding and sharing. Higher monthly income and the presence of children aged under 5 years were significantly associated with drug hoarding. Families with higher educational status were less likely to hoard and share medicines. The presence of stored drugs at home was significantly associated with the practice of selfmedication.

\section{Limitations of the Study}

Utilization of injectable medications administered in health facilities could not be assessed in this communitybased study. In addition, risky drug-sharing and selfmedication practices such as sharing leftover antibiotics with another person were not distinguished from non-risky practices such as sharing the right dose of non-expired paracetamol tablets among family members.

\section{Accessibility of Data and Materials}

The corresponding author will make the data sets available on reasonable request. 


\section{Abbreviations}

AOR, adjusted odds ratio; $\mathrm{CI}$, confidence interval; CNS, central nervous system; CSA, Central Statistical Agency; IRERC, Institutional Research Ethics Review Committee; NSAID, non-steroidal anti-inflammatory drug; OR, odds ratio; SD, standard deviation; WHO, World Health Organization.

\section{Ethical Approval and Consent to Participate}

The study was conducted in accordance with the Declaration of Helsinki. The ethical approval for this study was received from the Institutional Research Ethics Review Committee (IRERC) of the College of Health Sciences, Debre Tabor University (reference number DTU/re/54/99/2020). A letter of support was written from Debre Tabor University and further endorsement was carried out by the zonal health desk and administration department. The permission letter was submitted to officials at all levels down to the kebeles involved in the study. The interviewers explained the objective, advantage, and risks of the study, and respondents were briefed about their voluntary participation as well as the confidentiality of their response, to obtain informed consent from the participants before the data collection began.

\section{Consent to Publish}

All the authors have shown their agreement to publish this manuscript in this journal.

\section{Author Contributions}

All authors made a significant contribution to the work reported, whether that is in the conception, study design, execution, acquisition of data, analysis and interpretation, or in all these areas; took part in drafting, revising or critically reviewing the article; gave final approval of the version to be published; have agreed on the journal to which the article has been submitted; and agree to be accountable for all aspects of the work.

\section{Disclosure}

The authors report no conflicts of interest in this work.

\section{References}

1. WHO. What is Drug Utilization Research and Why is It Needed: Introduction to Drug Utilization Research. Oslo: Oslo Press; 2003.

2. Gama H. Drug utilization studies. Arquivos De Medicina. 2008;22(2/ 3):69-74.
3. Rana M, Shankar P, Dubey A, Mishra P, Subish P, Bhaskar PV. Drug utilization with special reference to antimicrobials in a sub-health post in Western. J Nepal Health Res Counc. 2005.

4. WHO. How to Investigate the Use of Medicines by Consumers. World Health Organization; 2004.

5. Bhartiy S, Shinde M, Nandeshwar S, Tiwari S. Pattern of prescribing practices in the Madhya Pradesh, India. Kathmandu Univ Med J. 2008;6(1):55-59.

6. WHO. The Rational Use of Drugs. Report of the Conference of Experts. Geneva: World Health Organization; 1985:2013.

7. Rasool BKA, Fahmy SA, Abu-Gharbieh EF, Ali HS. Professional practices and perception towards rational use of medicines according to WHO methodology in United Arab Emirates. Pharm Pract. 2010;8 (1):70.

8. WHO. Promoting Rational Use of Medicines: Core Components. World Health Organization; 2002.

9. Ofori-Asenso R, Agyeman AA. Irrational use of medicines - a summary of key concepts. Pharmacy. 2016;4(4):35. doi:10.3390/ pharmacy 4040035

10. Amare G, Gedif T, Alemayehu T, Tesfahun B. Pattern of drug use in Addis Ababa community. East Afr Med J. 1997;74(6):362.

11. Asefzadeh S, Asefzadeh M, Javadi H. Care Management: Adherence to Therapies Among Patients at Bu-Alicina Clinic, Qazvin, Iran. Journal of Research in Medical Sciences. 2005.

12. Asefzadeh S, Nassiri-Asl M. Drugs at home in Qazvin, Iran: community based participatory research. Eur J Sci Res. 2009;3(1):42-46.

13. Dap WHO. (1992) People's perceptions and use of drugs in zimbabwe: a socio-cultural research projects. World Health Organization. 1992.

14. Kiyingi KS, Lauwo JA. Drugs in the home: danger and waste. World Health Forum. 1993;14(4):381-384.

15. Yousif MA. In-home drug storage and utilization habits: a Sudanese study. Eastern Mediterranean Health J. 2002;8(2-3):422-431.

16. Temu-Justin M, Risha P, Mlavwasi Y, Makwaya C, Leshabari M. Availability and usage of drugs at household level i tanzania: case study in Kinondoni District, Dar es Salaam. East Central African J Pharmaceutical Sci. 2002;5(3):49-54.

17. Radyowijati A, Haak H. Determinants of antimicrobial use in the developing world: citeseer. Child Health Research Project Special Report. 2002.

18. Hussain S, Malik F, Ashfaq KM, et al. Prevalence of self-medication and health-seeking behavior in a developing country. African j Pharmacy Pharmacol. 2011;5(7):972-978.

19. Kadri R, Hegde S, Kudva AA, Achar A, Shenoy SP. Self-medication with over the counter ophthalmic preparations: is it safe? Int $J$ Biol Med Res. 2011;2(2):528-530.

20. Okumura J, Wakai S, Umenai T. Drug utilisation and self-medication in rural communities in Vietnam. Soc Sci Med. 2002;54 (12):1875-1886. doi:10.1016/S0277-9536(01)00155-1

21. Phalke V, Phalke D, Durgawale P. Self-medication practices in rural Maharashtra. Indian j Community Med. 2006;31(1):34. doi:10.4103/ 0970-0218.54933

22. Suleman S, Ketsela A, Mekonnen Z. Assessment of self-medication practices in Assendabo town, Jimma zone, southwestern Ethiopia. Res Soc Administrative Pharm. 2009;5(1):76-81. doi:10.1016/j. sapharm.2008.04.002

23. Bashrahil KA, Baruzaig AS. Self-medication: concept, prevalence \& risks in Mukalla City (Yemen) 2004-2005. Andalus Studies Res. 2008;2:1-3.

24. Quick JD. Management Sciences for Health. World Health Organization, Action Programme on Essential Drugs: Managing Drug Supply: The Selection, Procurement, Distribution, and Use of Pharmaceuticals. 2nd ed. West Hartford, Conn: Kumarian Press; 1997.

25. Ayalew MB. Self-medication practice in Ethiopia: a systematic review. Patient Prefer Adherence. 2017;11:401. doi:10.2147/PPA. S131496 
26. Sado E, Gedif T. Drug utilization at household level in Nekemte Town and surrounding rural areas, western Ethiopia: a cross-sectional study. Open Access Library J. 2014;1(03):1.

27. Gitawati R. Pattern of household drug storage. Kesmas: National Public Health J. 2014;9(1):27-31.

28. Foroutan B, Foroutan R. Household storage of medicines and self-medication practices in south-east Islamic Republic of Iran. EMHJ. 2014;20(9):547-553. doi:10.26719/2014.20.9.547

29. Jassim A-M. In-home drug storage and self-medication with antimicrobial drugs in Basrah, Iraq. Oman Med J. 2010;25(2):79. doi:10.5001/omj.2010.25

30. Abdo-Rabbo A, Al-Ansari M, Gunn B, Suleiman B, Suleiman HAL, Al-Lawati H. Household survey on medicine use in oman. directorate of rational use of medicines ministry of health muscat, sultanate of oman in collaboration with WHO/EMRO. JPRM. 2009;2008-2009.

31. Tsiligianni IG, Delgatty C, Alegakis A, Lionis C. A household survey on the extent of home medication storage a cross-sectional study from rural crete. Greece European J General Practice. 2012;18 (1):3-8.

32. Wieczorkiewicz SM, Kassamali Z, Danziger LH. Behind closed doors: medication storage and disposal in the home. Ann Pharmacother. 2013;47(4):482-489. doi:10.1345/aph.1R706

33. Mastroianni Pde C, Lucchetta RC, Sarra Jdos R, Galduróz JC. [Household storage and use of medications in a population served by the family health strategy in Brazil]. Revista panamericana de salud publica. 2011;29(5):358-364. doi:10.1590/s102049892011000500009

34. Tresànchez-Lacorte B, Figueras A. Medicines in western sahara refugee camps in tindouf: prescriptions and self-medication mixing in the drawer. Glob Public Health. 2020;1-7.

35. Abou-Auda HS. An economic assessment of the extent of medication use and wastage among families in Saudi Arabia and Arabian Gulf countries. Clin Ther. 2003;25(4):1276-1292. doi:10.1016/S01492918(03)80083-8
36. Ocan M, Bbosa GS, Waako P, Ogwal-Okeng J, Obua C. Factors predicting home storage of medicines in Northern Uganda. BMC Public Health. 2014;14(1):650. doi:10.1186/1471-2458-14-650

37. Wondimu A, Molla F, Demeke B, et al. Household storage of medicines and associated factors in Tigray Region, Northern Ethiopia. PLoS One. 2015;10(8):e0135650. doi:10.1371/journal.pone.0135650

38. Teni FS, Surur AS, Belay A, et al. A household survey of medicine storage practices in Gondar town, northwestern Ethiopia. BMC Public Health. 2017;17(1):238. doi:10.1186/s12889-017-4152-8

39. Enato EF, Sounyo AA, Einarson TR. Medication utilization and illness management study in Nigeria. Ann Pharmacother. 2011;45(7-8):924-930. doi:10.1345/aph.1Q051

40. Zargarzadeh A, Tavakoli N, Hassanzadeh A. A survey on the extent of medication storage and wastage in urban Iranian households. Clin Ther. 2005;27(6):970-978. doi:10.1016/S0149-2918(05)00122-0

41. Teni FS, Birru EM, Surur AS, et al. Pattern and predictors of medicine use among households in Gondar Town, northwestern Ethiopia: a community-based medicine utilization study. BMC Res Notes. 2017;10(1):357. doi:10.1186/s13104-017-2669-7

42. Arrais PS, Fernandes ME, Pizzol TD, et al. Prevalence of self-medication in Brazil and associated factors. Rev Saude Publica. 2016;50(suppl 2):13s. doi:10.1590/s1518-8787.2016050006117

43. Danhier A, Brieva J, Villegas G, Yates T, Pérez H, Boggiano G. [Use of drugs in a urban population]. Rev Med Chil. 1991;119(3):334-337. Spanish.

44. Worku S. Practice of self-medication in Jimma Town. Ethiopian $J$ Health Development. 2003;17(2):111-116.

45. Afolabi A. Factors influencing the pattern of self-medication in an adult Nigerian population. Ann Afr Med. 2008;7(3):120-127. doi:10.4103/1596-3519.55666

46. Tourinho FV, Bucaretchi F, Stephan C, Cordeiro R. Home medicine chests and their relationship with self-medication in children and adolescents. Jornal de Pediatria. 2008;84(5):416-422.
Drug, Healthcare and Patient Safety

\section{Publish your work in this journal}

Drug, Healthcare and Patient Safety is an international, peer-reviewed open-access journal exploring patient safety issues in the healthcare continuum from diagnostic and screening interventions through to treatment, drug therapy and surgery. The journal is characterized by the rapid reporting of reviews, original research, clinical, epidemiological and post-marketing surveillance studies, risk management, health literacy and educational programs across all areas of healthcare delivery. The manuscript management system is completely online and includes a very quick and fair peer-review system. Visit http://www.dovepress.com/testimonials.php to read real quotes from published authors. 